\title{
MEMÓRIA E VIVÊNCIA DE MULHERES NEGRAS EM CAROLINA MARIA DE JESUS E CONCEIÇÃO EVARISTO
}

\section{MEMORY AND EXPERIENCE OF BLACK WOMEN IN CAROLINA MARIA DE JESUS AND CONCEIÇÃO EVARISTO}

\author{
Victória Lopes Pacheco* \\ Flávio Pereira Camargo ${ }^{* * *}$
}

Resumo: O presente estudo tem como objetivo estabelecer o diálogo entre o livro Quarto de despejo: Diário de uma favelada, de Carolina Maria de Jesus, e os contos "Olhos d'água" e "Maria", inseridos em Olhos d'água, de Conceição Evaristo. Assim sendo, por meio de uma análise comparativa entre as narrativas de Evaristo e o diário de Carolina, tenciona-se encontrar os pontos de contato entre as obras em questão, a fim de identificar a representação de uma realidade potencialmente coletiva, haja vista que todas as narradoras dos textos estudados são mulheres negras, mães, em condição de pobreza - tanto Carolina Maria de Jesus, que conta parte de sua própria história, quanto as personagens de Evaristo. Para que isso se realize, faremos uso, principalmente, dos pressupostos teórico-críticos de Regina Dalcastagnè (2015), Margarete Aparecida de Oliveira (2015) e da própria Conceição Evaristo (2009), sobretudo o que se refere ao conceito de escre(vivência).

Palavras-chave: Conceição Evaristo; Carolina Maria de Jesus; Literatura de autoria feminina.

ABSTRACT: This study aims to establish a dialogue between the book Quarto de despejo: Diário de uma favelada, by Carolina Maria de Jesus, and the short stories "Olhos d'Água" and "Maria", inserted in Olhos d'Água by Conceição Evaristo. Thus, by means of a comparative analysis between Evaristo's narratives and Carolina's diary, we intend to find the similarities between the productions concerned, in order to identify the representation of a potentially collective reality, given that all narrators of the studied texts are black women, mothers, in poverty - both Carolina Maria de Jesus, who tells

\footnotetext{
"Graduação em Letras - Português pela Universidade Federal de Goiás, Brasil (2018), Mestranda da Universidade Federal de Goiás, Brasil. E-mail: lopesvique@gmail.com.

"* Doutorado em Letras e Linguística pela Universidade Federal de Goiás, Brasil (2012). Professor Associado, nível I da Universidade Federal de Goiás, Brasil. E-mail: camargolitera@gmail.com.
} 
part of her own story, and the characters of Evaristo. For this purpose, we will mainly use the theoretical-critical assumptions of Regina Dalcastagnè (2015), Margarete Aparecida de Oliveira (2015) and Conceição Evaristo (2009) herself, especially regarding the concept of escre(vivência).

KEYWords: Conceição Evaristo; Carolina Maria de Jesus; Women’s Writing.

\section{CONSIDERAÇÕES INICIAIS}

A autora Carolina Maria de Jesus, nascida na cidade de Sacramento, em Minas Gerais, antes de procurar papel - e qualquer outra coisa que pudesse vender ou comer -, teve outros trabalhos, como o de empregada doméstica. Mas foi justamente enquanto era catadora, morando na favela do Canindé, localizada em São Paulo, que ela escreveu seu diário intitulado Quarto de despejo: Diário de uma favelada (2018), publicado pela primeira vez em 1960, em que narra o passar de seus dias de 1955 até 1960, com alguns intervalos.

O jornalista Audálio Dantas foi o responsável por descobrir Carolina e seu diário. A publicação do texto, que foi traduzido para mais de dez idiomas e que em poucos meses atingiu a marca de 100 mil exemplares, gerou significativa repercussão e provocou a "excitação dos consumidores fascinados pela novidade, pelo inusitado feito daquela negra semianalfabeta que alcançara o estrelato" (DANTAS, 2018, p. 7).

Assim, ainda na juventude, o livro chegou às mãos da também mineira Conceição Evaristo que, segundo a autora de Olhos d'água (2017), sofreu forte impacto pela obra de Carolina Maria de Jesus, como disse em uma matéria realizada em 2015 pela TVE, no programa Nação. Ainda nesse depoimento, Evaristo conta que levou o diário em questão para dentro de casa, sendo lido também por seus familiares. De acordo com a escritora, a vivência e a fome de Carolina - ao contrário de como acontecia com quem olhava de fora e se compadecia com aquela rotina de tanto sofrimento - eram as mesmas dela e de sua família.

Evaristo (2009), no I Colóquio Mulheres em Letras, ocorrido na Universidade Federal de Minas Gerais, contou que sua mãe, ao ler Quarto de despejo, se identificou profundamente e, anos mais tarde, escreveu seu próprio diário - o que, para a escritora, constata o início de uma tradição, constituída a partir da obra de Carolina:

Guardo comigo esses escritos e tenho como provar em alguma pesquisa futura que a favelada do Canindé criou uma tradição literária. Outra favelada de Belo Horizonte seguiu o caminho de uma escrita inaugurada por Carolina e escreveu também sob a forma de diário, a miséria do cotidiano enfrentada por ela. (EVARISTO, 2009, s/p).

Tânia Franco Carvalhal (2007) ressalta que, na opinião de muitos teóricos das propostas clássicas da literatura comparada, para que um estudo comparativo acontecesse, era 
importante que houvesse a "existência de um contato real e comprovado entre autores e obras ou entre autores e países" e que essa perspectiva "abria caminho para os estudos de fontes e de influências; com isso, as investigações que se ocupavam em estabelecer filiações e em determinar imitações ou empréstimos recebiam grande impulso". (CARVALHAL, 2007, p. 13). Mais adiante, ela associa a concepção de filiação à de tradição: "ao preconizar a ideia de 'filiação', a definição se ampara num conceito de tradição no qual a cronologia (ou antecipação) se converte em critério dominante". (CARVALHAL, 2007, p. 31).

Porém, o objetivo desta pesquisa, ainda que sendo um estudo comparativo, não é comprovar filiação ou influência de uma autora sobre outra, até porque já é sabido que Evaristo leu a obra de Carolina, e que essa leitura a afetou demasiadamente. Não há necessidade de comprovação nesse sentido. Portanto, esta análise visa a estabelecer uma aproximação de viés temático, a partir da leitura do diário Quarto de despejo, de Carolina Maria de Jesus, e dos contos "Olhos d'água" e "Maria", de Conceição Evaristo, que compõem o livro Olhos d'água.

O objetivo é, desse modo, voltando o olhar para os pontos de contato entre os textos das autoras em questão, buscar perceber como, de maneiras diferentes, as duas tratam de uma mesma realidade - ou de realidades muito similares -, evidenciando, assim, que elas partem de vivências particulares, mas que acabam falando de uma experiência coletiva.

\section{A CONSTRUÇÃO DA MEMÓRIA}

Regina Dalcastagnè (2015), em texto inicialmente publicado no livro Africanidades e relações raciais (2014), salienta a importância das autoras e autores negros. Segundo ela, nas palavras dos escritores, ainda "se busca encontrar o espírito de um tempo e a voz de uma coletividade" e que "esta função, considerada tão elevada, é desempenhada por pessoas que, como todas as outras, refletem suas próprias trajetórias e suas circunstâncias peculiares". (DALCASTAGNÈ, 2015, s/p). Porém, afirma que o cânone literário brasileiro é feito de brancos.

De acordo com a pesquisadora, quando se olha para o que é considerado "literatura" - ou seja, para os textos que ocupam os currículos escolares, por exemplo -, é possível notar que a grande maioria das pessoas que a produziu ainda é do sexo masculino. Além disso, ela afirma que uma pesquisa em que ela analisou romances brasileiros "de 1990 para cá, revelou que menos de $5 \%$ dos autores são pretos ou pardos”. (DALCASTAGNÈ, 2015, s/p).

A crítica literária feminista vem exercendo um papel importante de se voltar para a produção de escritoras mulheres e para o modo como o ser feminino é representado na literatura. Contudo, a perspectiva feminista, apesar do seu mérito, muitas vezes ignorou, e ainda ignora, as vivências específicas das mulheres negras, como se o feminismo estivesse apenas a serviço das mulheres brancas de classe média. Para Djamila Ribeiro, autora de Quem tem medo do feminismo negro?, 
Em obras sobre feminismo no Brasil é muito comum não encontrarmos nada falando sobre feminismo negro. Isso é sintomático. Para quem é esse feminismo então? É necessário entender de uma vez por todas que existem várias mulheres contidas nesse ser mulher e romper com a tentação de universalidade, que só exclui. (RIBEIRO, 2019, p. 53).

Portanto, para analisar obras como as de Carolina Maria de Jesus e Conceição Evaristo, faz-se essencial lembrar de que se tratam de duas autoras mulheres, negras, que foram acometidas pela pobreza. Afinal, no Brasil, "a cor da pele - assim como o gênero ou a classe social - estrutura vivências distintas” (DALCASTAGNÈ, 2015, s/p), vivências essas que estão impressas na produção das autoras aqui estudadas.

O livro Quarto de despejo, para muitos, não pode ser considerado literatura. Evaristo e o escritor Jeferson Tenório, no programa já citado da TVE, contam que o diário não entra nos currículos escolares brasileiros. Mas, neste artigo, a intenção não é discutir se o volume é um livro literário ou, talvez, um documento sociológico. O que aqui interessa é que se trata de um texto que, mesmo não sendo ficcional e não estando dentro da norma culta, foi produzido a partir da experiência e da subjetividade de Carolina, em forma de diário.

Para Maurice Blanchot (apud OLIVEIRA, 2015, p. 33), o gênero diário deve ter compromisso com a verdade. Trata-se, segundo Margarete Aparecida de Oliveira, de um discurso memorialístico. Aponta também que:

O texto de Carolina exprime outro aspecto do diário não muito tratado nas teorias sobre o gênero, ou seja, o diário como um meio de denúncia ultrapassando a fronteira entre o pessoal e o coletivo ao expor cruamente a realidade miserável do favelado, revelando um espaço narrativo em que encontramos a crítica social, que é um traço marcante na escrita de autora, considerada também como literatura de testemunho. (OLIVEIRA, 2015, p. 34).

Esse testemunho, produzido por Carolina de Jesus, dialoga com a obra e a perspectiva de Conceição Evaristo. No conto “Olhos d'água”, o texto é construído - assim como em Quarto de despejo - a partir da memória da narradora. Essa, tentando se recordar de que cor eram os olhos de sua mãe, recorre às lembranças de sua infância, por não conseguir sequer se "lembrar de como havia chegado até ali”. (EVARISTO, 2017, p. 15).

A narrativa gira em torno de uma mãe, apesar de ser contada pela filha. A personagem materna muito se assemelha à Carolina Maria de Jesus. Trata-se de uma mulher negra, nascida no interior de Minas Gerais, que, pelo que se pode entender, cria suas filhas sozinha, sem um companheiro. Nada é dito a respeito do pai - ou dos pais - das crianças. A fome, questão mais insistente do diário de Carolina, também atinge a personagem. Quando não havia o que comer, brincava com suas filhas para tentar distraí-las. A família residia em um barraco que 
nos dias de chuva parecia que ia desabar, assim como o da catadora de papel, que reclama das goteiras e da dificuldade de trabalhar quando não fazia sol.

Está chovendo. Eu não posso ir catar papel. O dia que chove eu sou mendiga. Já ando mesmo trapuda e suja. Já uso o uniforme dos indigentes. E hoje é sábado. Os favelados são considerados mendigos. Vou aproveitar a deixa. A Vera não vai sair comigo porque está chovendo. (...) Ageitei o guarda-chuva velho que achei no lixo e saí. Fui no Frigorifico, ganhei uns ossos. Já serve. Faço uma sopa. Já que a barriga não fica vazia, tentei viver com ar. Comecei desmaiar. Então eu resolvi trabalhar porque eu não quero desistir da vida. (JESUS, 2018, p. 61).

Segundo a narradora do conto, as lembranças da infância da mãe se confundiam com as da sua própria. E, no caso deste texto, é a filha quem dá voz à figura materna e à sua memória. Provavelmente, os "olhos d'água” atribuídos à personagem sejam a maneira da narradora perceber e expressar como a mãe se sentia diante de todas as dificuldades por ela enfrentadas. O sofrimento da mulher, não verbalizado no conto, se materializa em lágrimas, quando ela "só ria de uma maneira triste e com um sorriso molhado" (EVARISTO, 2017, p. 17), ou nos momentos em que seus olhos "se confundiam com os olhos da natureza" (EVARISTO, 2017, p.17-18), com o choro sendo metaforizado pela chuva.

Nesse sentido, o que se nota em Quarto de despejo é o contrário. Carolina Maria de Jesus, por meio do diário e de tudo que escrevia, teve a oportunidade de registrar em palavras, a partir de seu próprio olhar, o seu descontentamento. Diz inclusive que, quando não tinha o que comer, ela escrevia em vez de xingar.

Ainda no texto de Regina Dalcastagnè (2015), ela aponta que, devido ao racismo estrutural instituído historicamente no Brasil, a população negra foi afastada dos espaços de poder e da produção de discurso. Por isso, uma mulher negra moradora da favela, com apenas dois anos de educação formal, teve sua obra recebida com tanta curiosidade, como se sua vivência fosse carregada de exotismo quando, na verdade, muito se parece com a de um gigantesco número de mulheres brasileiras.

A memória de Carolina de Jesus reproduzida em diário mostra o dia a dia da escritora. Essa é registrada de maneira imediata, logo depois que os fatos descritos ocorreram. Suas impressões, dessa maneira, são aproximadas. A autora fala do lugar em que vive sem saber se um dia realmente teria a oportunidade de sair dali, ou que proporção atingiria seu diário, mostrando a interpretação quase instantânea dos acontecimentos contados.

Já no conto de Conceição Evaristo, a memória evocada diz respeito à infância da narradora que, no momento no qual narra, já é adulta. Sua percepção do que se deu no passado advém de um distanciamento. O modo de compreender e organizar as lembranças dispostas na narrativa só se dá desse modo por conta do tempo decorrido. 
Ademais, pode-se entender também que a memória da mãe, da maneira como é construída, só pode ser evocada pela filha quando esta também já é mãe, em um processo de espelhamento. Não só as recordações da infância de cada uma se confundem, como também o conto se encerra com a filha da mulher que narra perguntando a ela "qual a cor tão úmida de seus olhos" (EVARISTO, 2017, p. 19), sendo, desse modo, o desfecho de um ciclo.

Luiz Henrique Silva de Oliveira define o que Evaristo chama de escre(vivência) como "a escrita de um corpo, de uma condição, de uma experiência negra no Brasil". (OLIVEIRA, 2009, p. 622). A autora diz que "a escrita e o viver se con(fundem)" (EVARISTO, 2009, s/p), o que muito diz a respeito de sua produção, que parece ter raízes profundas em sua própria vivência afrofeminina. Neste caso, seus textos, apesar de ficcionais, dizem muito dela e de toda uma coletividade. Afinal, se para Maurice Halbwachs (apud OLIVEIRA, 2015, p. 27) a memória é um fenômeno social, construído coletivamente, e não de maneira individual, autoras como Conceição Evaristo e Carolina Maria de Jesus, partindo da memória, falam não só por elas.

\section{MÃES NEGRAS, EM CONDIÇÃO DE POBREZA, E SUAS CARÊNCIAS}

Conceição Evaristo questiona a maneira recorrente de representação das mulheres negras na literatura, "ancorada nas imagens de seu passado escravo, de corpo-procriação e/ou corpo-objeto de prazer do macho senhor". (EVARISTO, 2005. p. 52). De acordo com a escritora, o discurso que modifica essa perspectiva e traz de um novo modo a imagem do ser feminino e negro é a autorrepresentação. As próprias escre(vivências) das autoras negras as colocam na posição de sujeito que descreve a si mesmo e fala de sua própria realidade e experiência.

No mesmo ensaio, Evaristo (2005) ressalta a falta de representação da mulher negra cumprindo o papel de mãe. Porém, a autorrepresentação consegue recuperar essa ausência, tanto no diário de Carolina Maria de Jesus, em que expõe diariamente sua vida como mãe, quanto nos contos de Evaristo aqui analisados - e em outros do livro Olhos d'água.

Em “Maria”, assim como acontece em “Olhos d'água”, a trajetória da mãe não é narrada por ela - mas, dessa vez, sendo realmente um conto em terceira pessoa, o que no anterior não acontece. Ao contrário do que acontece no primeiro, no qual diversas lembranças e pequenos episódios eram contados, "Maria” gira em torno de apenas um incidente. E os diálogos, com exceção de apenas uma fala em discurso direto, estão construídos por meio do discurso indireto livre.

No conto em questão, Maria, única personagem nomeada da história e personagem principal, está voltando da casa da patroa, com o que sobrara de uma festa desta última e uma gorjeta. No ônibus, ela encontra o pai de seu primeiro filho. Entretanto, após uma conversa com Maria, o homem e seu parceiro, que também estava no ônibus, assaltam as pessoas que lá estavam, a não ser Maria e um garoto negro. Em seguida, Maria, que fica no veículo depois 
que os homens saem, é linchada após a terem associado ao assalto, provavelmente por conta da cor de sua pele.

Maria, empregada doméstica, é negra e mãe solo, assim como as outras personagens centrais desta pesquisa. Ela, assim como no outro conto, muito se assemelha à Carolina Maria de Jesus. A maneira de lidar com a fome e a preocupação com os filhos diante de uma situação tão precária são extremamente parecidas:

Ela levava para casa os restos. O osso do pernil e as frutas que tinham enfeitado a mesa. Ganhara as frutas e uma gorjeta. O osso, a patroa ia jogar fora. Estava feliz, apesar do cansaço. A gorjeta chegara numa hora boa. Os dois filhos menores estavam muito gripados. Precisava comprar xarope e aquele remedinho de desentupir nariz. Daria para comprar também uma lata de Toddy. As frutas estavam ótimas e havia melão. As crianças nunca tinham comido melão. Será que os meninos iriam gostar de melão? (EVARISTO, 2017, p. 39-40).

Carolina teve três filhos de pais diferentes, e Maria também. Aqui, Maria mostra não só sua faceta materna, mas também a de mulher que se relaciona com homens, se apaixona, se sente sozinha e tem desejos - lado que não é mostrado em "Olhos d'água", por exemplo. Mostra-se, neste caso, que Maria, como todas, antes de mãe, é uma mulher que dispõe de vontades e carências.

A dificuldade prática de ser uma mãe que cuida de seus filhos sozinha é apresentada sem deixar de lado a parte afetiva e mesmo sexual. Além disso, o conto traz também a problemática de um homem que, apesar de cometer um crime, demonstra algum tipo de afeição em relação a Maria e seu filho, mostrando o lado humano de um assaltante, cuja subjetividade costuma ser ignorada.

Carolina Maria de Jesus, apesar de falar tanto da fome e da vida penosa na favela, também se relaciona com alguns homens durante o tempo em que escreveu o diário. Chega, inclusive, a se apaixonar por um cigano e a sofrer por ele. É possível notar, nesse sentido, que mesmo enfrentando situações de uma vivência - ou sobrevivência - absolutamente precária, Carolina, por vezes, deixa transparecer as faltas não materiais. Evaristo, na matéria feita pela TVE (2015), diz que ainda é necessário que se faça uma leitura humana de Carolina, que possui outras carências que ultrapassam a fome física.

Carolina de Jesus, entretanto, apesar de muitas vezes sentir falta de um companheiro, não se sujeitava a qualquer circunstância para ter um homem ao seu lado. Sobre as outras mulheres da favela, ela escreve:

Elas alude que eu não sou casada. Mas eu sou mais feliz do que elas. Elas tem marido. Mas, são obrigadas a pedir esmolas. São sustentadas por associações de caridade. 
Os meus filhos não são sustentados com pão de igreja. Eu enfrento qualquer especie de trabalho para mantê-los. E elas, tem que mendigar e ainda apanhar. Parece tambor. A noite enquanto elas pede socorro eu tranquilamente no meu barracão ouço valsas vienenses. Enquanto os esposos quebra as tabuas do barracão eu e meus filhos dormimos socegados. Não invejo as mulheres casadas da favela que levam vida de escravas indianas.

Não casei e não estou descontente. Os que preferiu me eram soezes e as condições que eles me impunham eram horríveis. (JESUS, 2018. p. 16-17).

Na filmagem, Evaristo afirma ver em Carolina de Jesus a "vivência de um feminismo, apesar de não estar teorizada". Tal conhecimento relacionado ao papel da mulher, segundo a autora de Olhos d'água, é prático, assim como suas percepções acerca da negritude.

Portanto, "Maria” e Quarto de despejo apresentam mães negras - fugindo da representação recorrente da mulher que não é branca - que são as matrizes e as sustentações de suas famílias, cuidando de seus filhos praticamente sozinhas.

Além disso, pode-se retomar o ponto da coletividade. Segundo dados do Instituto Brasileiro de Geografia e Estatística (IBGE), 57,3 milhões de lares são regidos por uma mãe solo, o que corresponde a uma porcentagem de $38,7 \%$. Assim sendo, a quantidade de figuras maternas que não podem contar com o(s) pai(s) de seu(s) filho(s) vai muito além de Carolina e das personagens de Evaristo.

Inclusive o nome da personagem, Maria, que intitula o conto, é uma possível ferramenta de identificação com milhares de mulheres brasileiras que passam por conflitos parecidos, por ser um nome tão comum - nome, inclusive, que compõe os de Carolina Maria de Jesus e de Maria da Conceição Evaristo, e também de todas as irmãs desta última. De acordo com Natanael Duarte Azevedo e Iran Ferreira de Melo, nessa narrativa "percebemos quantas outras Marias passam pelas mesmas violências físicas e simbólicas em seus cotidianos, seja dentro de casa ou na rua, com seus parceiros ou com desconhecidos". (AZEVEDO e MELO, 2017, p. 110).

\section{CONSIDERAÇÕES FINAIS}

De acordo com Conceição Evaristo, “a literatura surge como um espaço privilegiado de produção e reprodução simbólica de sentidos”. (EVARISTO, 2005, p. 52). Desse modo, é importante que existam autores e autoras distintos, com diferentes subjetividades e origens, que produzam literatura e sejam lidos. No entanto, não é o que costuma acontecer.

Como foi visto no texto de Regina Dalcastagnè (2015), a produção literária - a que é considerada literatura - no Brasil é um tanto quanto homogênea, o que não corresponde à realidade da população brasileira. Ao público, chega uma maioria de livros escritos por homens 
brancos. Assim, é possível reconhecer a importância de autoras como Evaristo e Carolina Maria de Jesus.

Essas, mulheres negras, escrevem a partir de suas experiências, indo contra a maré do cânone hegemônico. A sua representação, tanto na questão da autoria quanto na construção de personagens, traz um novo olhar para o que costuma acontecer na maior parte da produção literária deste país.

Articulando, por meio de uma comparação que une as obras pelo eixo temático, Quarto de despejo e os dois contos de Olhos d'água, foi possível notar muitos pontos de contato entre os três textos. E, ao estabelecer esse diálogo, observou-se que, se mulheres diferentes relatam vivências tão similares, isso é sintoma de uma coletividade perceptível nas narrativas analisadas neste artigo. Portanto, Carolina de Jesus e Evaristo, por meio de sua produção, falam por uma grande quantidade de mulheres negras que foram sistematicamente silenciadas por muitos anos, até os dias de hoje.

\section{REFERÊNCIAS}

AZEVEDO, N. D.; MELO, I. F. de. A construção do feminino em "Olhos d'água", de Conceição Evaristo: Uma análise de performances pós-identitárias de gênero. Línguas \& Letras, v. 18, p. 101-111, 2017-e-ISSN: 1981-4755.

BLANCHOT, M. O livro por vir. Trad. Leyla Perrone-Moisés. São Paulo: Martins Fontes, 2005.

CAROLINA MARIA DE JESUS. Nação, Porto Alegre: TVE, 18 set. 2015. Disponível em: <https:// www.youtube.com/watch?v=E5V8SvEN2lI>. Acesso em 02 jun. 2019.

CARVALHAL, T. F. Literatura comparada. $4^{a}$. ed. São Paulo: Ática, 2007.

DALCASTAGNÈ, R. Por que precisamos de escritoras e escritores negros? Grupo de Estudos em Literatura Brasileira Contemporânea. Brasília: 13 jun. 2015. Disponível em: $<$ https://gelbcunb. blogspot.com/2015/06/por-que-precisamos-de-escritoras-e.html>. Acesso em 04 jun. 2019.

DANTAS, A. A atualidade do mundo de Carolina. In: JESUS, C. M. de. Quarto de despejo: Diário de uma favelada. $10^{a}$. ed. São Paulo: Ática, 2018.

EFRAIM, A. Chefiando 39\% dos lares, mães solo ainda sofrem preconceito. Estadão, São Paulo, 08 mar. 2017. Acesso em: 10 jun. 2019.

EVARISTO, C. Olhos d'água. $1^{\mathrm{a}}$. ed. Rio de Janeiro: Pallas, 2017.

EVARISTO, C. Entrevista. 2009. Disponível em: <http://www.letras.ufmg.br/literafro/ autoras/188-conceicao-evaristo>. Acesso em 02 jun. 2019.

EVARISTO, C. Da representação à auto-representação da mulher negra na literatura brasileira. Revista Palmares: cultura afro-brasileira. Ano I, n. 1, agosto 2005 - ISSN 1087280. 
HALBWACHS, M. 1990. A memória coletiva. Trad. Beatriz Sidou. São Paulo: Centauro, 2006. JESUS, C. M. de. Quarto de despejo: Diário de uma favelada. 10ª ed. São Paulo: Ática, 2018. OLIVEIRA, L. F. S. de. "Escrevivência" em Becos da memória, de Conceição Evaristo. Revista Estudos Feministas, Florianópolis, 2009, p. 621-623.

OLIVEIRA, M. A. de. Narrativas de favela e identidades negras: Carolina Maria de Jesus e Conceição Evaristo. Belo Horizonte, 2015. Dissertação (Mestrado de Estudos Literários) Faculdade de Letras, UFMG.

RIBEIRO, D. Quem tem medo do feminismo negro? São Paulo: Companhia das Letras, 2019.

Recebido para publicação em 30 de Dezembro de 2019. Aceito para publicação em 3 de Março de 2020. 